\title{
Cutting ceramic by turning of nickel alloy Inconel
}

Ivan Mrkvica $^{1)}$, Miroslav Neslušan ${ }^{2)}$, Ryszard Konderla ${ }^{3)}$, Miroslav Janoš ${ }^{4)}$

${ }^{1)}$ Department of Machining and Assembly, Faculty of Mechanical Engineering, VSB-Technical Univerzity of Ostrava, Czech Republic. E.-mail: ivan.mrkvica@vsb.cz

${ }^{2)}$ Department of Machining and Manufacturing Engineering, Faculty of Mechanical Engineering, University of Žilina, Slovakia. E-mail: miroslav.neslušan@fstroj.uniza.sk

${ }^{3)}$ Hyundai Motor Czech s.r.o., Czech Republik. E-mail: ryszardkonderla@seznam.cz

${ }^{4)}$ Department of Machining and Assembly, Faculty of Mechanical Engineering, VSB-Technical Univerzity of Ostrava, Czech Republic. E.-mail: miroslav.j@hlucin.net

This article deals with dry turning of nickel superalloy - Inconel 718. The different ceramic inserts were applied for cutting process. These inserts were produced by Greenleaf Corporation company. This paper discusses durability of cutting inserts, the different intensity of tool wear at various cutting parameters. The most suitable cutting conditions are chosen in the scope of applied tools.

Keywords: turning, Inconel, cutting ceramic, tool wear, dry machining

\section{Acknowledgements}

This work was financially supported with project Increasing of Professional Skills by Practical Acquirements and Knowledge (CZ.1.07/2.4.00/17.0082) by Education for Competitiveness Operational Programme financed by Structural Founds of Europe Union and from the means of state budget of the Czech Republic and by the Students Grant Competition of VSB-TU Ostrava and Ministry of Education, Youth and Sports (SP2012/68) Effective machining of progressive materials and integrity surface evaluation.

\section{References}

[1] LI, H.Z.; ZENG, H.; CHEN, X.Q. An experimental study of tool wear and cutting force variation in the end milling of Inconel 718 with coated carbide inserts [online] 2006, [cit. 2010-10-05]. Dostupné z: WWW: $<$ http://www.sciencedirect.com/science>

[2] NESLUŠAN, Miroslav; CZÁN, Andrej. Obrábanie titanových a niklových zliatin, 1 vydání, Žilina: Žilinská univerzita v Žilině, 2001, 195 s. ISBN 80-7100-933-4

[3] KONDERLA, Ryszard; MRKVICA, Ivan. Soustružení niklové slitiny Inconel 718 nástrojem s VBD ze slinutého karbidu, Strojírenská technologie, 2011, roč. XVI, č. 3, s.13-20. ISSN 1211-4162.

[4] DŽUPON, Miroslav; JURKO, Jozef; GAJDOŠ, Mário; FERDINANDY, Milan; JAKUBECZYOVÁ, Dagmar. Plastická deformácia v okolí vŕtaných diel austenitickej ocele 1.4301. Chemické listy, Vol. 105, no. S (2011), p. 606-608. ISSN 0009-2770

[5] PANDA, Anton; JURKO, Jozef; DŽUPON, Miroslav; PANDOVÁ, Iveta. Optimalizácia tepelného spracovania ložiskových krúžkov s ciel’om eliminovat' deformácie material. Chemické listy, Vol. 105, no. S (2011), p. 459461. ISSN 0009-2770

[6] JURKO, Jozef; DŽUPON, Miroslav; PANDA, Anton; GAJDOŠ, Mário; PANDOVÁ, Iveta. Deformácia materiálu pod obrobeným povrchom pri výrobe dier vŕtaním do austenitickej nehrdzavejúcej ocele. Chemické listy, Vol. 105, no. 16 (2011), p. s600-s602. ISSN 0009-2770

[7] Specialmetals.com [online]. 27.6.2007 [cit. 2010-12-11]. Inconel alloy 718.pdf. Dostupné z WWW: $<$ http://www.specialmetals.com/documents/Inconel\%20alloy\%20718.pdf $>$.

[8] Suppliersonline.com [online]. (c) 2009 [cit. 2010-12-11]. Inconel718.asp. Dostupné z WWW: $<$ http://www.suppliersonline.com/propertypages/Inconel718.asp $>$.

[9] BIBUS - Výpis produktu: [online]. (c) 2010 [cit. 2010-12-13]. Inconel-alloy_718a718 SPF_725.pdf. Dostupné z WWW: <http://new.bibus.cz/pdf/Special_Metals/Nikl /prehled/inconel-alloy_718a718SPF_725.pdf>.

[10] KONDERLA, R. Možnosti suchého obrábění niklových slitin, Disertační práce, Ostrava: VŠB-TU Ostrava, $2011,135 \mathrm{~s}$.

[11] MÁDL, Jan; RÁZEK, Vítězslav; KOUTNÝ, Václav; VLČEK, Igor. Vlastnosti povrchu po tvrdém obrábění. Strojírenská technologie, 2008, roč. XIII., č. 3, s. 27-31. ISSN 1211-4162. 
[12] KOCMAN, Karel; PROKOP, Jaroslav. Cutting Tools for Hard Material Turning. Manufacturing Technology, 2008, vol. IV, p. 5-10. ISSN 1213248-9. 